\title{
A argumentação e o ensino dialógico da Filosofia
}

\section{Maurício Colenghi Filho}

Mestre em Ensino, História e Filosofia das Ciências e Matemática pela Universidade Federal do ABC (UFABC), Brasil. Docente da Faculdade SESI-SP de Educação.

colenghi@yahoo.com.br

\section{Patrícia Del Nero Velasco}

Doutora em Filosofia pela Pontifícia Universidade Católica de São Paulo (PUC/SP) e docente da Universidade Federal do ABC (UFABC), Brasil.

patricia.velasco@ufabc.edu.br

Resumo: Considerando a argumentação como parte constituinte do filosofar, o presente texto tem como objetivo defender a presença de conteúdos e habilidades lógicoargumentativas como fundamental ao ensino e à aprendizagem da Filosofia. Trata-se, contudo, de uma presença que deve ocorrer na prática dialógica, exigindo do professor, portanto, um papel bastante preciso: o de, na esteira de Sócrates, convidar seus interlocutores a refletirem, a ouvirem atentamente, a fundamentarem e eventualmente reverem seus pontos de vista, respeitando posicionamentos distintos dos seus. Nesse sentido, a prática argumentativa em sala de aula, em última instância, configura-se em um compromisso político: um compromisso com a liberdade de expressão, com o diálogo aberto ao pluralismo de pontos de vista - experiência singular de exercício público e compartilhado do conhecimento.

Palavras-chave: Argumentação. Filosofar. Ensino de Filosofia. Papel do Professor. Diálogo.

Abstract: Considering argumentation as a constituent part of the act of philosophizing, the present text aims to defend the presence of logical-argumentative contents and skills as fundamental to the teaching and learning of Philosophy. It is, however, a presence that must occur in the dialogical practice, therefore, the teacher plays a precise role: like Socrates, invite their interlocutors to reflect, to listen carefully, to substantiate and possibly to review their views, respecting different positions from theirs. In this sense, the argumentative practice in the classroom is a political commitment: a commitment to freedom of expression, to open dialogue to pluralism of views - unique experience of public and shared exercise of knowledge.

Keywords: Argumentation. Philosophize. Philosophy Teaching. Teacher's role. Dialogue. 
Introdução

O presente artigo insere-se no movimento crescente, no Brasil e na América Latina, de pensar o ensino da Filosofia como indissociável das escolhas categorial e axiológica feitas pelo professor diante das perguntas "o que é filosofia?" e "que filosofia ensinar?" - questões que se vinculam à própria natureza do saber filosófico ${ }^{1}$.

No texto aqui compartilhado, todavia, não adentraremos a discussão sobre a natureza da Filosofia; assumiremos simplesmente que o filosofar pressupõe três componentes elementares e, portanto, a prática de ensino de Filosofia deve ser também constituída por estes elementos, quais sejam, a problematização, a conceituação e a argumentação².

Os pressupostos nos quais nos embasamos são largamente defendidos na literatura da área. Em sua obra Filosofia em sala de aula: teoria e prática para o ensino médio (2009), Lídia Maria Rodrigo afirma:

Um ensino de filosofia que privilegie esses três aspectos [problematização, conceituação e argumentação] pode garantir uma didática especificamente filosófica, além de criar a possibilidade de trabalhar, juntamente com os conteúdos filosóficos, aquelas competências que o aluno do ensino médio ainda não possui (RODRIGO, 2009, p. 56)

Na obra citada, a autora se ampara nas pesquisas de Michel Tozzi, filósofo francês que sustenta que:

Aprender a filosofar é, então, desenvolver sobre as noções e problemas essenciais para todo o homem, estas três capacidades: problematizar as questões e afirmações, conceituar as noções, argumentar sobre as teses e objeções. Passos estreitamente articulados, já que, por exemplo, nós problematizamos ao argumentar sobre as objeções, elaboramos uma problemática ao definir as noções que colocamos em relação, argumentamos a partir de uma questão (TOZZI, 1999 apud RODRIGO, 2009, p.53-54, grifos nossos)

Os aspectos formais do pensamento e da aprendizagem filosófica a que faz menção Tozzi, encadeados no processo de filosofar, representam uma possibilidade de estruturar não só a resposta que o professor dá ao problema da natureza do saber filosófico, como também a própria filosofia que ele

\footnotetext{
${ }^{1}$ Para reflexões sobre o ensino de filosofia como problema filosófico, conferir o livro de mesmo nome, do argentino Alejandro Cerletti (2009).

2 Para uma proposta de reflexão sobre a similaridade entre a natureza da argumentação e da Filosofia, assim como uma discussão sobre o próprio papel da argumentação na construção de cada Filosofia, conferir Velasco (2017).
} 
propaga em sala de aula e em suas estratégias didáticas. No presente artigo, interessa-nos aprofundar a reflexão sobre um dos aspectos em questão, a argumentação, explorando seu papel no ensino dialógico da Filosofia. Antes, porém, cabe uma digressão, ainda que brevíssima, sobre os outros dois aspectos formais do pensamento filosófico.

\section{Problematização e conceituação filosóficas}

A filosofia não é um a priori da razão. Ela nasce de uma atitude humana de admiração, o thaumazein. Admira-se sempre diante de algo, de algum fato, de algum outro, de algum fenômeno. Esse admirar-se não é um simples maravilhar-se ou um estupefar-se frente ao mundo, mas é uma aspiração ao saber, uma aspiração que vai tomando a forma de um problema e, mais especificamente, de um problema filosófico. Mas o que caracteriza o problema filosófico? Nas palavras de Cerletti,

[...] o que faz com que uma interrogação possa ser considerada filosófica, fundamentalmente, está mais na intencionalidade de quem pergunta, ou se pergunta, do que na pergunta em si. [...] seu traço distintivo é aspirar a um saber sem supostos. Por isso, o perguntar filosófico não se conforma com as primeiras respostas que costumeiramente são oferecidas, que, em geral, interrompem o perguntar pelo aparecimento dos primeiros supostos. Mas como um saber sem supostos é impossível, o questionar filosófico é permanente (CERLETTI, 2009, p. 23-24)

O sintoma de que o sujeito foi "picado pelo bicho da filosofia" é a inquietação, a não conformação com as primeiras respostas que costumeiramente são oferecidas ao problema. As respostas são tentativas de acomodar e apaziguar o problema. É a colocação dos supostos. "O interrogar filosófico [...] se constitui, fundamentalmente, no re-perguntar. Ao fim e ao cabo, não é outra coisa senão a incômoda insistência do velho Sócrates em perfurar as afirmações até fazê-las cambalear, ou até que sejam capazes de mostrar sua fortaleza" (CERLETTI, 2009, p. 24-25).

O problema filosófico não é apaziguável porque não dá para ser respondido tecnicamente desde uma perspectiva da ciência, do direito ou de qualquer outro saber. Ele não se "con-forma" aos supostos, pois tem outra intencionalidade, ou seja, a intencionalidade de examinar, de perfurar os supostos em direção a uma universalidade. Essa universalidade é a busca pelo conceito, o conceito que dá suporte à construção de todos os supostos que pretendem lançar luzes esclarecedoras sobre o problema, mas não o esgotar. 
[...] O deslocamento que se produz, por exemplo, entre a apreciação de uma pintura bela e a conceitualização da beleza significa uma emigração desde uma circunstância particular em direção à universalidade das ideias. A inquietude filosófica abre o horizonte do que "se diz", ou do que diz a ciência, a arte, etc., para recompô-lo no plano do puro conceito e assim extremar a sua significação (CERLETTI, 2009, p. 25)

O mundo é potencialmente fértil de problemas filosóficos, esperando que os seres humanos lancem sobre ele o seu gérmen que é constituído da admiração (thaumazein). Esse gérmen, quando lançado ao mundo, é fecundo e possibilita a irrupção do problema. Por sua vez, o problema filosófico, tão concreto e mundano, instaura-se na razão humana perturbando-a incessantemente, até levá-la ao ponto de devolver para este mundo, agora problematizado, um conceito. Talvez seja essa uma das possíveis contribuições da filosofia para o mundo humano: pensá-lo, dando inteligibilidade à experiência, compreendendo-a através de conceitos que sirvam de ferramentas para que possamos nos posicionar e agir na concretude do mundo.

Os conceitos dados ao mundo, entretanto, são como plantas que precisam ser regadas e adubadas para que não murchem e morram. O que então dá vigor aos conceitos são as asserções que buscam explicitá-los e fazêlos claro, desdobrando-os e revelando-os na correlação com o problema. Esse edifício de asserções que explicitam o conceito filosófico compreende a argumentação. Sem saber argumentar, ou seja, sem saber encadear premissas e conclusões e sem saber avaliar e justificar a coerência dessas inferências não é possível fazer com que o conceito cresça e floresça - assim como uma planta quando não lhe são oferecidas condições adequadas de desenvolvimento. As condições adequadas para o desenvolvimento e comunicabilidade do conceito, seja para ser avaliado, corroborado, criticado, reformulado em novas bases ou rechaçado, exigem dos sujeitos competências lógico-argumentativas, sem as quais a atividade filosófica encontra-se comprometida, correndo-se o risco de aleijar a própria filosofia. Possuir competências lógico-argumentativas é conseguir mobilizar os conceitos, explicitá-los para responder aos problemas como apresentaremos na seção subsequente.

\section{O argumentar como aspecto formal da aprendizagem filosófica}

Como supra referido, o argumentar é um dos aspectos invariáveis da atividade filosófica e, portanto, deve fazer-se presente em qualquer perspectiva filosófica assumida pelo professor na sua prática de ensino. Lídia 


\section{$\mathrm{El} \square \mathrm{dA}$}

Revista Eletrônica de Estudos Integrados em Discurso e Argumentação, Ilhéus, n. 18, abr.2019.

Maria Rodrigo considera que enquanto "o conceito permite saber precisamente do que se fala, a argumentação determina até que ponto aquilo que se diz pode ser considerado verdadeiro" (2009, p. 62). A atividade filosófica é engendrada no conceito e na argumentação, por isso pede-se de toda filosofia a apresentação de boas razões, justificando de forma clara e coerente as afirmações que se faz a partir dos conceitos.

Entre os sujeitos que compõem o ambiente escolar, para além dos estudantes e do professor de filosofia, é recorrente a ideia de que a filosofia se presta à argumentação. Todavia, alguns daqueles não familiarizados com o saber filosófico usualmente pensam que argumentar é apenas expor suas opiniões, sem preocupação em justificar rigorosamente aquilo que se expõe, confundindo argumentar com discutir. Como afirma Anthony Weston, "discutir é uma espécie de luta verbal" (2005, p.13); já a argumentação filosófica não se reduz e nem se identifica com uma discussão ou debate superficial sobre pontos de vista.

De forma geral, argumentar filosoficamente compreende disponibilizar um conjunto de justificativas que embasam, dão suporte ou, ainda, que oferecem dados favoráveis à conclusão. Também denominada tese, a conclusão consiste na ideia central que se demonstra e se busca defender com razoabilidade. Os argumentos são tentativas de sustentar os conceitos com razões, expandindo-os em forma de tese.

Um sujeito que efetivamente argumenta tem uma pretensão racional e não está simplesmente defendendo uma opinião, uma crença ou um ponto de vista de forma irrefletida, inflamada e/ou descompromissada com o rigor da justificação. Quem argumenta, implicitamente está fazendo um pedido ao seu interlocutor: pede a este que também, de forma racional e avaliando suas justificações, Ihe dê atenção e que considere o que ele afirma, as suas asserções, ou ainda, que aquilo que ele tem a dizer seja levado a sério. Só que o quanto será levado a sério a asserção e a tese (ou as teses) do argumentador depende de muitas circunstâncias. Dentre outras possibilidades, pode-se dar credibilidade a uma tese fundamentando-se no prestígio, na autoridade ou até na admiração que se tem pelo argumentador. Porém, se a credibilidade e a aceitação do argumento residem exclusivamente na pessoa que argumenta, então esta argumentação não representa uma atividade filosófica. 
Uma argumentação filosófica deve abrir (e deixar aberto) um espaço para que o argumentador e o interlocutor contestem as asserções e as teses: "Qualquer que seja a natureza de uma asserção específica [...] sempre se pode, em cada caso, contestar a asserção e pedir que se preste atenção aos fundamentos em que a asserção se baseia (suporte, dados, fatos, evidências, indícios, considerações, traços)" (TOULMIN, 2006, p. 16). São estes fundamentos dos quais dependem o mérito do argumento. Na prática da atividade filosófica, argumentos podem e devem ser contestados; porém, estas possíveis contestações só poderão ter de fato credibilidade se elas formarem outros bons argumentos que estejam no mínimo à altura do padrão do argumento contestado.

Neste sentido, expor um argumento é abrir um caminho de investigação. Vejamos o exemplo dado por Weston:

\begin{abstract}
Alguns filósofos e activistas argumentaram [...] que criar animais só para produzir carne causa um sofrimento imenso aos animais e que, portanto, é injustificado e imoral. Será que têm razão? Não podemos decidir consultando nossos preconceitos. Estão envolvidas muitas questões. Por exemplo, temos obrigações morais para com outras espécies ou o sofrimento humano é o único realmente mau? Podem os seres humanos viver realmente bem sem carne? Alguns vegetarianos vivem até idades muito avançadas. Será que este facto mostra que as dietas vegetarianas são mais saudáveis? Ou será irrelevante, tendo em conta que alguns não vegetarianos também vivem até idades muito avançadas? (É melhor perguntarmos se há uma percentagem mais elevada de vegetarianos que vivem até idades avançada.) Terão as pessoas mais saudáveis tendências para se tornarem vegetarianas, ao contrário das outras? Todas estas questões têm de ser apreciadas cuidadosamente, e as respostas não são, à partida, óbvias (WESTON, 2005, p. 14, grifos nossos)
\end{abstract}

De fato, as respostas não são óbvias. Não se pode chegar a uma conclusão baseada em boas razões sobre se é injustificável e imoral criar animais para o consumo humano sem antes compreender e analisar filosoficamente conceitos como: imoralidade, obrigações morais, espécie, sofrimento, humanidade. A investigação filosófica dos conceitos (o que exige perpassar a história da filosofia), relacionando-os com o problema colocado, apresenta subsídios para o desenvolvimento da argumentação.

Não é recomendável que os estudantes de nível médio apenas repitam as conclusões dos filósofos que defendem os direitos dos animais só porque Ihes parecem bons argumentos. Eles podem até serem convencidos pelas razões e dados apresentados. Podem assumir as mesmas conclusões dos filósofos, não há problema nisso, pois assumir o mesmo posicionamento não significa necessariamente aderi-lo de forma automatizada. Contudo, é 
necessário que estes estudantes aprendam a mobilizar e se distanciar das percepções que tiveram diante dos argumentos apresentados, que consigam refletir e explicar racionalmente tais percepções, amparados pelas ferramentas conceituais e que, em um segundo momento, apresentem argumentativamente suas próprias justificativas e elucidem para si mesmos e para os outros as asserções que os convenceram, formando agora seu posicionamento filosófico.

Se o estudante ficar convencido de que se deve mudar o trato humano com os animais, por exemplo, terá de usar argumentos para explicar como chegou a essa conclusão: é assim que poderá estabelecer uma interlocução filosófica com outros sujeitos. Por outro lado, desde que apresentem outros bons argumentos contrários, fundamentados filosoficamente em conceitos e boas asserções, não há problema (do ponto de vista da lógica argumentativa) em defender a tese contrária. Alguns estudantes poderiam alegar que existe uma cadeia alimentar natural, uma hierarquia das espécies, na qual os animais também estão aí para servirem à alimentação humana e, portanto, para estes alunos não haveria problemas éticos em criá-los para servir de comida para os humanos (ainda que em grandes confinamentos e numa lógica instrumentalizada).

O traço distintivo de uma argumentação filosófica reside no fato de que nela as conclusões são necessariamente acompanhadas de suas respectivas justificações, e estas, por sua vez, são amparadas na problematização e na discussão conceitual. Aprender a justificar as conclusões que se chegam, atentando aos conceitos que as constituem: eis aí uma das tarefas do ensino de filosofia, visto que ele não pode se limitar à mera identificação das asserções e apreensão das teses, ainda que estes exercícios de identificação e apreensão sejam muito importantes. O ensino de filosofia deve munir os estudantes de conceitos e competências que os auxiliem na compreensão do itinerário das asserções por meio do qual as teses se estabelecem e se sustentam em um ensaio argumentativo. $E$ mais do que isso: devem também se aventurar, na especificidade de seu contexto, a construir ensaios argumentativos ${ }^{3}$.

Deve-se salientar que, a despeito de uma rica bibliografia que toma a noção de interação como cerne da argumentação ${ }^{4}$, adotamos no presente artigo a concepção mais arraigada na literatura filosófica que considera a

\footnotetext{
${ }^{3}$ Para uma proposta de prática de ensino filosófico a partir de ensaios argumentativos, conferir Colenghi Filho (2017).

${ }^{4}$ Conferir, por exemplo, as obras de Rui Grácio (2010, 2016) e Christian Plantin (2008, 2010).
} 
inferência como conceito-chave da argumentação. Trata-se de uma concepção que se convencionou chamar de lógica informal e que busca oferecer métodos de crítica para a avaliação coerente de argumentos.

Os métodos supracitados são indispensáveis tanto para exprimir de modo inteligível o pensamento quanto para a boa compreensão daquilo que se comunica e se aprende. Nesse sentido, a lógica pode ser "utilizada a fim de determinar se o argumento é correto ou não, pois a lógica não nos ensina como inferir: indica-nos, porém, que inferências podemos aceitar. Procede ilogicamente a pessoa que aceita inferências incorretas" (SALMON, 1987, p. 28-29). Uma vez que a argumentação é um dos pilares da atividade filosófica, entende-se que o ensino da filosofia deveria contemplar a apresentação didática de conceitos-chave de lógica, ferramentas indispensáveis tanto para a identificação de bons e maus argumentos quanto para a construção de (bons) argumentos próprios 5 .

Portanto, no trato com a argumentação, exigem-se do ensino de filosofia dois movimentos distintos e complementares, os quais podem ser executados de modo concomitante. Deve-se, por um lado, oferecer aos estudantes certos conceitos e conteúdos lógicos - ferramentas que, não representando um fim em si mesmo, constituem uma condição para o filosofar. Pode-se explorar o que são inferências, premissas e conclusões. Ademais, podem-se trabalhar outras noções caras à lógica, as quais permitem a avaliação de argumentos: as definições e modelos de argumentos dedutivos e indutivos, os atributos valorativos próprios de argumentos dedutivos (validade e correção) e próprios de argumentos indutivos (força e solidez). Pode-se, outrossim, apresentar algumas falácias mais presentes nos discursos cotidianos ${ }^{6}$.

Apresentados aos estudantes os conteúdos colhidos na seara da lógica, é esperado que eles mobilizem tais conhecimentos em direção à construção de competências lógico-argumentativas. Trata-se aqui do segundo movimento requerido do ensino da Filosofia no trato com a argumentação: a identificação de premissas e conclusões em textos filosóficos e não-filosóficos e a

\footnotetext{
5 Para uma introdução às noções elementares de lógica informal relacionadas à prática argumentativa e uma familiarização com sua estrutura conceitual, pensando sua aplicabilidade na Educação Básica, o leitor pode conferir Velasco, 2016. Para uma série de exercícios de identificação de estrutura de argumentos filosóficos, conferir Bruce e Barbone (2013).

6 Nota-se que, como anteriormente observado, se está aqui adotando a perspectiva da argumentação centrada na noção de inferência e, portanto, considera-se falho ou falacioso o argumento cujas premissas não dão suporte razoável para a conclusão (seja por serem irrelevantes, seja por incorrerem em ambiguidades linguísticas). Sobre os tipos e exemplos clássicos de falácias não formais, conferir Velasco (2016) e Almossawi (2017).
} 
identificação de argumentos complexos e seus respectivos subargumentos, assim como o exercício de fundamentar suas próprias teses, desdobrar os conceitos em justificações e elucidações, convencer seus interlocutores sobre a razoabilidade daquilo que se defende, refutar ideias ou responder a objeções, reconhecer e considerar as teses dos outros.

Em nossa proposta, a lógica - área da filosofia que tem os argumentos como objeto de estudo - ocupa um papel relevante no ensino de filosofia no nível médio, o que não é usual nos currículos oficiais ${ }^{7}$. Além do mais, grande parte dos materiais didáticos de filosofia ou não apresentam conteúdos de lógica ou, quando apresentam, o fazem de uma maneira formalizada e simbólica, simplesmente oferecendo regras e formas de argumentos silogísticos ou, igualmente, preceitos formais e gerais do que intitulam de "lógica simbólica". Costuma-se não atentar às relações entre lógica e argumentação e, principalmente, não é usual o trabalho de identificação e avaliação de argumentos em linguagem ordinária.

Apesar da falta de tradição da temática da argumentação no escopo do ensino da Filosofia no Brasil, julgamos que o trabalho com conteúdos e habilidades lógico-argumentativas é primordial no ensino-aprendizagem da Filosofia na Educação Básica - seja por conta do argumentar ser um dos aspectos formais do pensamento filosófico (como anteriormente discutido), seja porque defendemos que o exercício da capacidade argumentativa potencializa também o exercício de um tipo de cidadania democrática e responsável:

[...] a valorização positiva da argumentação remete, sobretudo, para a sua importância do ponto de vista pessoal e de cidadania. É pois, de uma perspectiva prática, política e sociológica que ela é considerada. Nela a racionalidade está essencialmente ligada à noção de justiça, adquirindo o argumentar um valor sócio-simbólico que a liga a valores democráticos como o pluralismo, a nãoviolência, a liberdade e o direito às opiniões (GRÁCIO, 2009, p. 120)

Dado seu objetivo central, não cabe no escopo do presente trabalho explorarmos o caráter civilizatório da argumentação. Para tanto, o leitor pode recorrer a Grácio (2009). Não obstante, à guisa de conclusão desta seção, fazemos coro às palavras de Gustavo Bernardo em sua obra Educação pelo

\footnotetext{
${ }^{7}$ Consideram-se, aqui, os currículos nacionais. Sabe-se que em outros países a lógica figura como conteúdo central no ensino da Filosofia. Em Portugal, por exemplo, dentre as aprendizagens essenciais para $010^{\circ}$ ano do ensino secundário, consta um módulo inteiro dedicado à tese, argumento, validade, verdade e solidez; quadrado da oposição; formas de inferência válida; principais falácias formais; o discurso argumentativo e principais tipos de argumentos e falácias informais. Disponíve em: http://www.dge.mec.pt/sites/default/files/Curriculo/Aprendizagens_Essenciais/10_filosofia.pdf. Acesso: 05 mar. 2019.
} 
Argumento: "A ênfase no argumento chama a atenção para a necessidade do diálogo com o outro e, por via de consequência, para a necessidade do argumento que oriente, de maneira civilizada (sem o que, para que? - o porrete seria suficiente), todo diálogo, todo debate, toda discussão" (BERNARDO, 2000, p. 12).

\section{O papel do professor no exercício da argumentação em sala de aula}

Como companheiro de viagem dos seus estudantes no exercício do filosofar, o professor tem algumas funções a ele atribuídas. Na primeira etapa da atividade filosófica em sala de aula - a da possibilidade de irrupção do problema filosófico - o professor deve saber contar histórias, empreender narrativas. Na segunda etapa, no trato com o conceito, ele deve saber estabelecer pequenas "perturbações" no contrato didático ${ }^{8}$ e, finalmente, na terceira etapa da viagem, a da capacidade de argumentar, o professor deve fazer-se um "parteiro" de ideias, nos moldes do velho Sócrates de Atenas, na Grécia Antiga.

Era assim que Sócrates filosofava e auxiliava seus interlocutores a filosofar. Apresentava razões para suas teses e também pedia de seus interlocutores que demonstrassem as razões de suas conclusões sobre problemas filosóficos. Solicitava estas razões de seus debatedores, mas, no entanto, de forma ao mesmo tempo sagaz e generosa, auxiliava-os a apresentarem estas razões apontando equívocos, lacunas e contradições na argumentação. Lançava mão de exemplificações, analogias e perguntas concisas e diretas, formuladas a partir das asserções do interlocutor, com o intuito de que este último analisasse as fragilidades e erros do seu pensamento e o retomasse de forma mais consistente. Era o eficaz método

\footnotetext{
${ }^{8}$ O conceito de "contrato didático" foi proposto pelo educador matemático francês Guy Brousseau. De modo geral, significa que no cotidiano da sala de aula existe a priori um conjunto muitas vezes implícito de expectativas entre estudantes e professor na relação ensino e aprendizagem, donde alguns aspectos desse conjunto se explicitam como cláusulas do Contrato Didático estabelecido. Desse modo, o Contrato Didático administra as relações entre professor e estudante no processo de ensino e aprendizagem de um dado saber. Contudo, segundo Brousseau, há um paradoxo nessa tríade professor-estudante-saber: o professor deve proceder de maneira a não deixar tudo explícito ao estudante para não colocar em risco sua aprendizagem; por outro lado, se ele não faz a necessária mediação, rompe com o contrato. Portanto, as características de um Contrato Didático não são definidas apenas a partir da natureza da área ou especificamente pelo tema-objeto de estudo, mas, também, em função da concepção de mundo, e ainda, neste caso específico, da concepção de filosofia e ensino de filosofia das quais o professor é portador.
} 
socrático da ironia e da maiêutica, na tentativa de explicitar melhor o conceito através da argumentação9.

Em suma, ninguém saía de um diálogo com Sócrates da mesma maneira que entrou. Saía com um conhecimento autoconstruído. Nem sempre estes diálogos levavam de fato a uma conclusão efetiva, a um consenso ou ao convencimento do interlocutor por Sócrates. O mais importante, na atividade dialógica socrática, era o benefício de cada um de abandonar a doxa - termo grego que designa opinião, conhecimento impreciso e sem fundamento - e se colocar no caminho da episteme, do conhecimento refletido e crítico que aspira à sabedoria.

Através dos diálogos socráticos que conhecemos pelas obras de Platão, temos exemplos de como Sócrates procedia com o seu método e se fazia um “parteiro de ideias”. No diálogo Górgias (PLATÃO, 2002), por exemplo, na interlocução entre Sócrates e Polo, e que depois é retomada na discussão com Cálicles, o filósofo demonstra argumentativamente as razões que o levam a defender a tese de que "é melhor sofrer uma injustiça que praticá-la" (MARCONDES, 2009, p. 21). Em outro diálogo, intitulado Menão (1980), Sócrates está dialogando com o próprio Menão sobre se é possível ensinar a virtude (aretè). Diante das dificuldades para se construir uma tese, Sócrates muda a questão para o seu interlocutor e pergunta: “o que é a virtude?”. Na sequência, Menão apresenta exemplos do que seria a virtude e Sócrates argumenta contra essa tentativa de definir um conceito (no caso, o de virtude) por meio de exemplos. Sócrates conduz o diálogo levando seu interlocutor a compreender que precisaria de uma definição geral para o conceito, capaz de tornar os exemplos compreensíveis como casos particulares de um tipo universal e abstrato. Deveriam buscar, juntos, um conceito. Estava lançado o desafio do filosofar.

São nos moldes socráticos que o professor de filosofia deve requisitar dos seus estudantes a argumentação. Os meios para isso são vários: debates, produções audiovisuais, produção de texto em diversos gêneros etc. A partir

\footnotetext{
9 Sócrates é a principal personagem dos diálogos platônicos. Na literatura filosófica, é usual a identificação de dois momentos dos diálogos mediados por Sócrates: a ironia e a maiêutica. No primeiro, o patrono da filosofia ocidental partia das opiniões de seus interlocutores sobre suas atividades ou ramo de conhecimento para interrogá-los sobre o sentido das palavras empregadas. A intenção era mostrar, fazendo uso da ironia que nomeia este momento, a falta de precisão conceitual e a precariedade dos argumentos. O interlocutor era levado, pois, a reconhecer a própria ignorância com relação ao assunto em pauta. Em um segundo momento, intitulado de maiêutica, Sócrates auxiliava seus interlocutores a "parir" ideias próprias e bem constituídas, afastando-se do senso comum.
} 
das reflexões dos estudantes, o professor pode fazer-se um "Sócrates" não para pensar por eles ou conduzi-los a pensar como o professor gostaria que pensassem, mas para ajudá-los, a partir do diálogo, a depurar as argumentações, adentrando ainda mais no caminho da experiência filosófica.

Nessa perspectiva, a metodologia dialógica adotada pelo professor favorece tanto a prática argumentativa quanto a problematização filosófica, fomentando, igualmente, o espírito colaborativo em sala de aula. Nas palavras de Lipman:

No diálogo [...] o desequilíbrio é provocado a fim de forçar um movimento progressivo. [...] cada argumento evoca um contra-argumento que se impulsiona a si mesmo além do outro e impulsiona o outro além de si mesmo.

Uma conversa é uma troca de sentimentos, pensamentos, informações, interpretações. Um diálogo é um exame, uma investigação, um questionamento. [...] Aqueles que se envolvem em um diálogo fazem-no de maneira colaborativa (LIPMAN, 1995, p. 336)

Assim sendo, se, por um lado, escapa ao professor a pretensão socrática de conseguir que seus interlocutores se questionem a si mesmos, examinando seus conhecimentos e ações, por outro, os participantes envolvidos no diálogo em sala de aula acabam por exercitar uma série de habilidades imprescindíveis à formação: refletir, ouvir atentamente, enxergar alternativas, fundamentar pontos de vista, rever posições, aceitar posicionamentos diferentes dos seus etc. Logo, o ensino e a aprendizagem da argumentação, por meio do diálogo, implica, em última instância, em um compromisso político de todos os participantes:

É um compromisso com a liberdade, com o debate aberto, com o pluralismo, com o autogoverno e com a democracia. Só na medida em que os indivíduos têm a experiência de dialogar com outros iguais, de participar da investigação pública partilhada é que são capazes de, eventualmente, desempenhar um papel ativo na formação de uma sociedade democrática (SHARP, 1996, p. 44-45).

\section{Considerações finais}

O filosofar pressupõe três aspectos formais do pensamento: argumentar, problematizar e conceituar. Aspectos que se alimentam mutuamente: admirados, problematizamos o mundo que nos cerca, refletindo sistematicamente sobre este e buscando interrogar os supostos em direção à universalidade; esta, por sua vez, é encontrada em cada conceito criado pelo filósofo, os quais carecem de elucidação e sustentação. A fundamentação 
destes conceitos e de suas interrelações é dada pelos argumentos, decisivos para nossas escolhas filosóficas: a argumentação permite mobilizarmos os conceitos e explicitá-los a fim de respondermos os problemas postos.

Uma vez que o filosofar pressupõe a problematização, a conceituação e a argumentação, estes aspectos formais do pensamento devem estar presentes em um ensino filosófico da Filosofia. Para tanto, o professor deve saber empreender narrativas; saber provocar pequenas perturbações no interior do contrato didático e saber fazer-se um "parteiro de ideias" nos moldes do método dialógico que caracterizou a vida filosófica de Sócrates.

Os conceitos lógico-argumentativos não são, contudo, apenas conteúdos a serem ministrados. São requeridos apenas à medida que auxiliam na exigência de clareza e sistematicidade na produção e avaliação de argumentos. A prática argumentativa, por sua vez, ocorre em uma dinâmica dialógica - permitindo a redução das distâncias entre os sujeitos que compõem o ambiente escolar de aprendizado e possibilitando vivências que envolvem, primordialmente, o respeito mútuo imprescindível às sociedades democráticas: “Às vezes o ponto de vista tem certa miopia, / Pois enxerga diferente do que a gente gostaria / Não é preciso por lente nem óculos de grau / Tampouco que exista somente um ponto de vista igual / O jeito é manter o respeito e ponto final" (CAVALCANTI; KRIEGER, 2011).

\section{Referências}

ALMOSSAWI, Ali. O Livro Ilustrado dos Maus Argumentos. Tradução: Leila Couceiro. Ilustrações de A. Giraldo. Rio de Janeiro: Sextante, 2017.

BERNARDO, Gustavo. Educação pelo argumento. Rio de Janeiro: Rocco, 2000.

BRUCE, Michael; BARBONE, Steven. Os 100 argumentos mais importantes da Filosofia Ocidental. Tradução: Ana Lucia da Rocha Franco. São Paulo: Cultrix, 2013.

CAVALCANTI, João; KRIEGER, Eduardo. Ponto de vista. Casuarina. Álbum: Trilhos Terra Firme. Lançamento: 2011.

CERLETTI, Alejandro. O ensino de filosofia como problema filosófico. Tradução: Ingrid Müller Xavier. Belo Horizonte: Autêntica, 2009.

COLENGHI FILHO, Maurício. A produção de textos dissertativos-argumentativo como materialização da experiência de pensamento filosófico realizada por estudantes do ensino médio. EBR - Educação Básica Revista, v. 3, n. 1, p. 49-72, 2017. 
GRÁCIO, Rui Alexandre. Com que é que se parece uma argumentação? Representações sociais do argumentar. Comunicação e Sociedade, v. 16, p. 101-122, 2009.

. A interacção argumentativa. Coimbra: Grácio Editor, 2010.

. A argumentação na interação. Coimbra: Grácio Editor, 2016.

LIPMAN, Matthew. O pensar na educação. Tradução: Ann Mary Fighiera Perpétuo. Petrópolis: Vozes, 1995.

MARCONDES, Danilo. Textos Básicos de Ética: de Platão a Foucault. Rio de Janeiro: Jorge Zahar, 2009.

PLANTIN, Christian. A Argumentação: história, teorias, perspectivas. Tradução: Marcos Marcionilo. São Paulo: Parábola Editorial, 2008.

- A argumentação. Tradução: Rui Alexandre Grácio e Martina Matozzi. Coimbra: Grácio Editor, 2010.

PLATÃO. Menão. Tradução: Carlos Alberto Nunes. Belém: EDUFPA, 1980.

PLATÃO. Górgias. Tradução: Carlos Alberto Nunes. 2. ed. rev. Belém: EDUFPA, 2002.

RODRIGO, Lídia Maria. Filosofia em sala de aula: teoria e prática para o ensino médio. Campinas: Autores Associados, 2009.

SALMON, Wesley C. Lógica. Tradução: Álvaro Cabral. Rio de Janeiro: Guanabara/Koogan, 1987.

SHARP, Ann Margaret. Comunidade de Investigação: Educação para a Democracia. In: A Comunidade de Investigação e a Educação para o Pensar. Tradução: Ana L. Falconi e Melanie Wyffels.. Centro Brasileiro de Filosofia para Crianças. São Paulo, 1996. p. 37-47.

TOULMIN, Stephen E. Os usos do argumento. Tradução: Reinaldo Guarany. São Paulo: Martins Fontes, 2006.

VELASCO, Patrícia Del Nero. Educando para a Argumentação: contribuições do ensino da lógica. Belo Horizonte: Autêntica, 2016.

. Sobre o lugar da argumentação na Filosofia como disciplina. Educação e Filosofia, v. 31, n. 61, p. 517-538, jan./abr. 2017.

WESTON, Anthony. A arte de argumentar. Tradução: Desidério Murcho. 2. ed. Lisboa: Gradiva, 2005.

\section{Forma de citação sugerida}

COLENGHI FILHO, Maurício; VELASCO, Patrícia Del Nero. A argumentação e o ensino dialógico da Filosofia. EID\&A - Revista Eletrônica de Estudos Integrados em Discurso e Argumentação, llhéus, n. 18, p. 90-103, abr.2019. DOI dx.doi.org/10.17648/eidea-18-2306. 